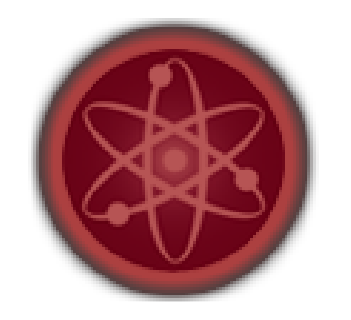

\title{
JOURNALRU
}

Назарчук Ю.И.

Приднестровский государственный университет им. Г.В. Плеханова Приднестровье, Тирасполь

doi: 10.18411/1j2016-2-17

\section{Информационные технологии в переводе}

За последние время структура спроса и предложения на рынке переводческих услуг кардинально изменилась. В условиях постоянного увеличения объема переводимых текстов особенно остро встал вопрос о поддержании высокого качества перевода при неуклонно растущей скорости его выполнения. Сегодня именно информационно-коммуникационные технологии являются, во-первых, мощнейшим инструментом оптимизации перевода как процесса, а во-вторых, эффективным и доступным средством контроля качества перевода как результата.

Ученые с давних пор пытались создать автоматические машинные переводчики, функционирующие без участия человека. И хотя на данном уровне развития пока еще невозможна полная автоматизация процесса перевода, деятельность переводчиков нового тысячелетия стала немыслимой без использования новых информационных технологий и электронных инструментов, направленных на ускорение и облегчение процесса перевода, к которым относятся электронные многоязычные переводные и одноязычные толковые словари, доступные в онлайновом или офлайновом режимах; автоматические машинные переводчики (наиболее известными являются 
программные продукты компании PROMT); системы класса Translation Memory (TRADOS, Déjà Vu,Wordfast и др.); программы автоматического редактирования текстов; электронные библиотеки; электронные энциклопедии; электронные словари (Lingvo, «МультиЛекс», «Мультитран»,«Контекст», Polyglossum); терминологические базы данных; и, наконец, сама глобальная сеть Интернет как хранилище невероятного объема информационных ресурсов.

Например, А.Н. Усачева подчеркивает, что «с появлением Интернета переводчик приобрел уникальную возможность выхода в мировую информационную сеть, ему стали доступны данные отовсюду. Изменения, которые это внесло в профессию переводчика, настолько колоссальны, что все последствия этого сейчас вряд ли возможно оценить» $[3,82]$. Умение применять все вышеперечисленные и другие электронные средства позволяет оптимизировать труд переводчиков (в особенности письменных) и повышает их конкурентоспособность на рынке переводческих услуг.

В данной статье мы рассмотрим некоторые из вышеперечисленных интернет ресурсов и попытаемся рассмотреть их достоинства и недостатки.

Системы машинного перевода осуществляют автоматизированный перевод текста. Единицами перевода при этом служат слова или словосочетания, причем последние разработки позволяют учитывать морфологию переводимого слова. «Развитые системы машинного перевода осуществляют перевод по заданным разработчиком и/или корректируемым пользователем алгоритмам перевода» [2, 40]. Для осуществления машинного перевода в компьютер вводится специальная программа, реализующая алгоритм перевода, под которым понимается последовательность однозначно и строго определенных действий над текстом для нахождения переводных соответствий в данной паре языков Яз1 -Яз2 при заданном направлении перевода (с одного конкретного языка на другой). Система машинного перевода включает в себя «двуязычные словари, снабженные необходимой грамматической информацией (морфологической, синтаксической и семантической) для обеспечения передачи 
эквивалентных, вариантных и трансформационных переводных соответствий, а также алгоритмические средства грамматического анализа, реализующие какуюлибо из принятых для автоматической переработки текста формальных грамматик» [1, 110]. Имеются также отдельные системы машинного перевода, рассчитанные на перевод в рамках трех и более языков, но они в настоящее время являются экспериментальными.

В настоящее время существует две концепции развития систем машинного перевода:

1. Модель большого словаря со сложной структурой, которая заложена в большинство современных программ-переводчиков;

2. Модель «смысл-текст» впервые сформулированная А.А. Ляпуновым, но пока не реализована нив одном коммерческом продукте[2, 60].

На сегодняшний день наиболее известны такие системы машинного перевода, как PROMT 200/ XT компании PROMT; Retrans Vista компаний Vista и Advantis; Сократ- набор программ Арсеналь.

Рамки статьи не позволяют подробно описать особенности всех упомянутых системах машинного перевода, поэтому предлагаю поговорить об одном из них: в системах семейства PROMT разработано практически уникальное по полноте морфологическое описание для всех языков, с которыми системы умеют обращаться. Оно содержит 800 типов словоизменений для русского языка, более 300 типов, как для немецкого, так и для французского языка, и даже для английского, который не принадлежит к флективным языкам, выделено. более 250 типов словоизменений. Множество окончаний для каждого языка хранится в виде древесных структур, что обеспечивает не только эффективный способ хранения, но и эффективный алгоритм морфологического анализа. Вместо принятого лингвистического подхода, предполагающего выделение последовательных процессов анализа и синтеза предложения, в основу архитектуры систем было положено представление процесса перевода как процесса с "объектно-ориентированной" организацией, основанной на 
иерархии обрабатываемых компонентов предложения. Это позволило сделать системы PROMT устойчивыми и открытыми. Кроме того, такой подход дал возможность применения различных формализмов для описания перевода разных уровней. В системах работают и сетевые грамматики, близкие по типу к расширенным сетям переходов, и процедурные алгоритмы заполнения и трансформаций фреймовых структур для анализа сложных предикатов.

Описание лексической единицы в словарной статье, которое фактически не ограничено по размерам и может содержать множество различных признаков, тесно взаимосвязано со структурой алгоритмов системы и структурировано не на основе извечной антитезы синтаксис - семантика, а на основе уровней компонентов текста. При этом системы могут работать и с не полностью описанными словарными статьями, что является важным моментом при открытии словарей для пользователя, от которого нельзя требовать тонкого обращения с лингвистическим материалом. В системе выделяется уровень лексических единиц, уровень групп, уровень простых предложений и уровень сложных предложений. Все эти процессы связаны и взаимодействуют иерархически в соответствии с иерархией текстовых единиц, обмениваясь синтезируемыми и наследуемыми признаками. Такое устройство алгоритмов позволяет использовать разные формальные методы для описания алгоритмов разных уровней.

В настоящее время компьютеры занимают все более значительное место не только среди программистов и инженеров, но и в среде самых разнообразных пользователей, включая лингвистов, переводчиков и специалистов. нуждающихся в оперативном переводе иноязычной информации. В этой связи программы, осуществляющие машинный перевод, являются очень удобным подручным средством в целях экономии времени и оптимизации процесса понимания иноязычной информации. Кроме того, сейчас имеются программыпереводчики, которые могут производить более или менее адекватный перевод 
иноязычного текстов и могут являться подспорьем в работе специалистов разных профилей.

\section{Литература:}

1. Нелюбин Л.Л. Компьютерная лингвистика и машинный перевод. М., ВЦП, 1991. - $151 \mathrm{c}$.

2. Семенов А.Л. Современные информационные технологии и перевод // Учебное пособие для студ. высш. учеб. заведений/ - М.: Издательский центр «Академия», 2008. - 224c.

3. Усачева, А. Н. Инновационные технологиив профессиональном переводе / А. Н. Усачева //Коммуникативные аспекты современной лингвистики и лингводидактики : материалы Междунар.науч. конф., г. Волгоград, 29 янв. 2008 г. - Волгоград : Волгогр. науч. изд-во, 2008. - С. 81-87.

4. Википедия - онлайн-энциклопедия [Электронный ресурс]. - Режим доступа: http://ru.wikipedia.org 